\title{
Effectiveness of Tympanic Thermometry for diagnosing Acute Otitis Media
}

\author{
Muhammad Zubair ${ }^{1}$, Ghulam Saqulain ${ }^{2}$, Arfat Jawaid ${ }^{3}$ \\ ${ }^{1}$ Audiologist, Isra University, Islamabad \\ ${ }^{2}$ Head, Department of ENT, CDA Capital Hospital, Islamabad \\ ${ }^{3}$ ENT Surgeon, Department of ENT, FC Hospital, Quetta
}

\section{ABSTRACT}

\begin{abstract}
Background: Acute Otitis Media (AOM) is a common upper respiratory tract infection (URTI) in children and usually presents with fever and otalgia. AOM is characterized by congested tympanic membrane and possible increase in temperature, which might be picked up by infrared tympanic thermometry. The objective of this study was to compare the temperature difference of tympanic membrane of affected ear with the unaffected ear and axilla in unilateral acute otitis media, and compare it with the control group.

Material and Methods: This case control study comprised of 200 cases of both genders, aged up to 5 years. They were divided into two groups; Group A included 100 clinically diagnosed cases of acute otitis media (AOM), who reported in the ENT Outpatient Department (OPD) and Group B included 100 controls who presented in General Filter Clinic with no ear complaints. Cases with chronic ear disease, ear discharge, and use of local drugs including ear drops, impacted ear wax, tragal tenderness and congenital malformations of the ear were excluded by taking a detailed history. Clinical examination including otoscopy by an expert was done before subjecting patients to axillary and tympanic thermometry measurements and data recording. Data was collected and tabulated using Microsoft Excel Worksheet and analyzed by SPSS 16. Qualitative data like gender were presented as percentage and ratio, while means and standard deviation were calculated for the quantitative data. Difference between the means of experimental and control groups were analyzed by independent sample t-test and $P$ value of less than or equal to 0.05 was taken as significant.
\end{abstract}

Results: This study included 100 cases of unilateral AOM and 100 normal controls without AOM. In patients with AOM, the mean temperature difference between the affected ear and axilla was $1.41^{\circ} \mathrm{F}$ as compared to $0.075^{\circ} \mathrm{F}$ in controls $(p=0.026)$. While the mean temperature difference between the affected ear and other ear was $0.65^{\circ} \mathrm{F}$ as compared to $0.19^{\circ} \mathrm{F}$ in controls $(\mathrm{p}=0.069)$.

Conclusion: In acute otitis media, the temperature of affected ear is significantly higher than axilla but was not significantly higher than the other ear. The finding may help establish thermometry as a diagnostic tool in clinics manned by doctors not competent to do otoscopy.

Key words: Axillary temperature, Infrared tympanic thermometer, Otitis media, Tympanic temperature

\begin{tabular}{lll}
\hline Authors' Contribution: & Correspondence: & Article info: \\
1,2 Conception, synthesis, planning of & Ghulam Saqulain & Received: January 8, 2019 \\
research and manuscript writing & Email: ghulam_saqulain@yahoo.com & Accepted: April 19, 2019
\end{tabular}

Interpretation, discussions, Active

participation in data collection ${ }^{3}$ Data

analysis.

Cite this article. Zubair M, Saqulain G, Jawaid A. Effectiveness of Tympanic Thermometry for

Diagnosing Acute Otitis Media. J Islamabad Med Dental Coll.2019; 8(2):74-78

Funding Source: Nil

Conflict of Interest: Nil

\section{Introduction}

Ear temperature accurately reflects core body temperature ${ }^{1}$, since the eardrum shares blood supply with the thermostat in the hypothalamus. Tympanic infrared thermometry is increasingly being used to rapidly measure body temperature. Acute Otitis Media (AOM) is a common upper respiratory tract infection URTI in children ${ }^{2}$, with an incidence of 256/1000 person-years in Europe $^{3}$ and a high overall incidence per 1000 personyears of 138, 207, 105 and 99 respectively reported for Pakistan, Saudi Arabia, Oman, and Turkey in a 
multinational study by Mustafa et al. ${ }^{4}$. AOM usually presents with fever and otalgia. In a study by Liese et al., earache was reported in $68.3 \%$, redness of the tympanic membrane in $67.3 \%$, ear discharge in $16.9 \%$ and spontaneous perforations in $7.1 \%$ of children presenting with AOM. ${ }^{3}$ In young children, crying, rubbing and holding of the ear, may suggest earache, however it becomes difficult for the physician to know the exact cause of fever in children who are unable to share their complaints. Diagnosis of AOM in such cases would require otoscopy. AOM is characterized by congested tympanic membrane and possible increase in temperature, which might be picked up by infrared tympanic thermometry.

This study was conducted to see whether there is an increase in tympanic temperature as measured by tympanic thermometry in ears affected by acute otitis media, as compared to normal ear and temperature in axillary region. This will serve to see if tympanic thermometry can be used as a screening tool by nonotologists to diagnose AOM especially in basic health units and in pediatric setups. The present study is important since no study has come up from Pakistan and because our basic health units are devoid of personnel trained in otoscopy.

\section{Material and Methods}

This is a case control study in which clinically diagnosed children of AOM of both genders, and up to 5 years of age, who presented in the ENT outpatient department (OPD) and General Filter Clinic of Capital Hospital, Capital Development Authority (CDA), Islamabad from January 2014 to December 2016, were included. Cases with discharging ears, those using local medications like ear drops, any ear disease, tragal tenderness, otitis externa, congenital deformities of ear and impacted wax were excluded from the study.

Patients were divided into two groups. Group A (experimental group) comprised of 100 clinically diagnosed cases of acute otitis media who reported in ENT OPD, and Group B (control group) included 100 cases who presented in filter clinic of outpatient. A detailed history including, chronic ear disease, ear discharge, use of ear drops was obtained by an otolaryngologist who also ruled out conditions like ear wax impaction, tragal tenderness etc., by otoscopy and confirmed presence of $\mathrm{AOM}$ in the experimental group before the patient underwent axillary and tympanic thermometry measurements. In all the patients, axillary temperature (AT) was noted at 3 minutes using a calibrated mercury thermometer and tympanic temperature was measured with the help of a calibrated infra-red thermometer (Braun Thermoscan IRT4020) using a new lens filter for each measurement. For each recording, thermometer probe was gently but snuggly fitted in the ear canal ensuring its direction to the TM (avoiding any discrepancy in measurement). ${ }^{5}$

The data included qualitative variables like gender and quantitative variables like age, tympanic temperature right ear (TTR), tympanic temperature left ear (TTL) and axillary temperature. Data was collected, tabulated and analyzed using Microsoft Excel Worksheet. Tympanic temperature minus axillary temperature was calculated for both experimental and control groups. Temperature of affected ear minus other ear was calculated for patients of AOM in experimental group while temperature difference of right and left ears was calculated for normal individuals in control group.

Data was collected and tabulated using Microsoft Excel Worksheet and analyzed by SPSS 16. Qualitative data was calculated and presented as percentage and ratio, while means were calculated for the quantitative data. Difference between the means of experimental and control groups was analyzed by independent sample ttest and $P$ value of less than or equal to 0.05 was taken as significant. The data was then compared with the literature available from different parts of the world and other parts of the country and deductions made and discussed.

\section{Results}

The total study population analyzed $(n=200)$ was divided equally into two groups. Group A (Experimental group) included 58 (58 \%) males and $42(42 \%)$ females, with male to female ratio of 1.4:1. Group B (Control group) included $81(81 \%)$ males and $19(19 \%)$ females with male to female ratio of $4.3: 1$. In group $A$, age range of $A O M$ 
patients was from 4 months to 4 years with a mean age of $2.8 \pm 0.96$ years and in group $B$, age range of the controls was from 1 year to 5 years with a mean age of $3 \pm 0.97$ years (Table I).

\begin{tabular}{|l|l|c|c|}
\hline \multicolumn{4}{|c|}{ Table I: Demographic data of the study population (n=200) } \\
\hline & & Group A & Group B \\
\hline \multirow{2}{*}{$\begin{array}{l}\text { Gender } \\
\mathbf{n}(\%)\end{array}$} & Male & $58(58 \%)$ & $81(81 \%)$ \\
\cline { 2 - 4 } $\begin{array}{l}\text { Age } \\
\text { (Years) }\end{array}$ & Female & $42(42 \%)$ & $19(19 \%)$ \\
\cline { 2 - 4 } & Minimum & 0.3 & 1.0 \\
\cline { 2 - 4 } & Maximum & 4.0 & 5.0 \\
\cline { 2 - 4 } & Mean & 2.8 & 3.0 \\
\cline { 2 - 4 } & Median & 3.0 & 3.1 \\
\cline { 2 - 4 } & Mode & 3 & 3 \\
\hline
\end{tabular}

Table II shows the temperature difference between the ear and axilla in Group A, mean temperature difference and standard deviation between the affected ear and axilla of $1.41 \pm 1.470 \mathrm{~F}$. While in Group $\mathrm{B}$, the mean temperature difference and standard deviation between the ear and axilla was $0.075 \pm 1.80 \mathrm{~F}$ with $P$ value less than 0.026 , which is statistically significant.

\begin{tabular}{|c|c|c|c|c|}
\hline \multicolumn{5}{|c|}{$\begin{array}{c}\text { Table II: Independent sample test statistics for temperature } \\
\text { difference between Pair } 1 \text { and Pair } 2\end{array}$} \\
\hline Variables & $\begin{array}{l}\text { Temperature } \\
\text { Difference }\end{array}$ & $\begin{array}{l}\text { Levene's } \\
\text { Test for } \\
\text { Equality } \\
\text { of } \\
\text { Variance }\end{array}$ & $\begin{array}{l}\text { T-Test for } \\
\text { Equality of } \\
\text { Means }\end{array}$ & \multirow[t]{2}{*}{$\begin{array}{c}P \\
\text { Value }\end{array}$} \\
\hline Pair 1 & (Mean + SD) & (F, Sig.) & $t$ & \\
\hline Group A: & $1.41 \pm 1.47$ & \multirow[b]{2}{*}{$.815, .374$} & \multirow[b]{2}{*}{2.344} & \multirow[b]{2}{*}{.026} \\
\hline Group B & $.075 \pm 1.80$ & & & \\
\hline Pair 2: & & \multirow{3}{*}{$.178, .676$} & \multirow{3}{*}{1.880} & \multirow{3}{*}{.069} \\
\hline Group A & $0.65 \pm 0.78$ & & & \\
\hline Group B: & $0.19 \pm 0.65$ & & & \\
\hline
\end{tabular}

Note: Group A = Experimental Group, Group B = Control Group Pair 1:

Group A: Tympanic temperature of affected ear minus axillary temperature Group B: Tympanic temperature of normal ear minus axillary temperature Pair 2:

Group A: Tympanic temperature of affected ear minus normal ear Group B: Tympanic temperature of right ear minus left ear in control

Regarding the temperature difference between both the ears, in Group A, 77 out of 100 patients had unilateral AOM. In these patients the mean difference and standard deviation between the temperature of affected ear and the other ear is $0.65 \pm 0.78{ }^{\circ} \mathrm{F}$. While in the first 77 individuals in the control group the mean temperature difference and standard deviation, between the temperature of right and left ear is $0.19 \pm 0.65^{\circ} \mathrm{F}$. The observed difference is not statistically significant as the calculated $P$ value is more than $0.05(P=0.069)$.

\section{Discussion}

Body core temperature is a vital sign with no test that can be labelled as gold standard for clinical temperature assessment. Core temperature should actually be measured from the pulmonary artery ${ }^{1}$, which is not accessible clinically. Conventionally body temperature is measured by taking an intraoral sublingual, rectal, axillary and even skin temperature, usually with a mercury thermometer. However, a number of drawbacks made physicians stick to axillary temperature measurement since this is safe and easily accessible in children. However, doubts regarding accuracy of axillary temperature exist. ${ }^{6}$ Tympanic temperature reflects core body temperature.1,7 Advent of Infrared tympanic thermometry has made this vital sign recording possible within seconds. Acute otitis media (AOM) being very common in childhood 3 and being an infective/ inflammatory condition, increase in temperature in the tympanic cavity is very likely.

Several authors have searched the effect of different pathologies of the ear on thermometry in a hope to use this vital sign for ear pathologies. ${ }^{8-13}$ Robb and Shahab, studied thermometry in otitis media with effusion (OME) with no effect on temperature. 8 Terndrup and Wong found elevated rectal temperature in cases with acute otitis media, ${ }^{13}$ and Aniutin et al., found increased difference between tympanic and axillary temperatures in exudative otitis media (EOM). ${ }^{11}$ Kelly and Alexander did not find significant temperature difference in suppurative and nonsuppurative otitis media with either the other ear or oral and rectal temperatures. ${ }^{14}$ Presence of wax may reduce the temperature measurement. ${ }^{12}$ In this study we found that the temperature of affected ear in acute otitis media was significantly higher than axillary temperature but was not significantly higher than the other ear, with mean temperature difference between the affected ear and 
axilla being $1.41^{\circ} \mathrm{F}$ as compared to $0.075^{\circ} \mathrm{F}$ in controls $(p=0.026)$. However, the mean temperature difference between the affected ear and other ear was $0.65^{\circ} \mathrm{F}$ as compared to $0.19^{\circ} \mathrm{F}$ in controls $(P=0.069)$. Similarly, Dogan et al., found higher temperature in tympanic than axillary thermometry. ${ }^{9}$ Brennan et al concluded in their study that tympanic thermometry was not useful for diagnosis of AOM, when compared to reference temperatures without $\mathrm{AOM}$ and the other ear in case of unilateral AOM.10 We also did not find any significant difference between temperatures of the two ears in case of unilateral AOM. Therefore, increase in tympanic temperature compared to axillary temperature in patients with acute otitis media may be used in diagnosing in nonotologic setup. This could be especially helpful in young children who cannot volunteer a history. Jolin et al., studied the utility of tympanic thermometry in diagnosing acute suppurative otitis media (ASOM) and found it useful. ${ }^{15}$ The mean temperature difference between the two ears for children with unilateral ASOM was $0.39^{\circ} \mathrm{C} \pm$ $0.29^{\circ} \mathrm{C}$ in their study, while the mean temperature difference in control group was $0.23^{\circ} \pm 0.15^{\circ} \mathrm{C}$. They concluded that tympanic thermometry may be useful in diagnosing ASOM when used with other clinical data. In our study, although the mean temperature of affected ear was $0.65^{\circ} \mathrm{F}$ higher than the other ear, but it was not statistically significant as a difference of $0.19{ }^{\circ} \mathrm{F}$ was found between the two ears in controls as well $(P=0.069)$.

We suggest that the temperature difference between the affected ear and axilla is more useful in diagnosing AOM than the difference between the two ears. Also, since AOM is bilateral in many cases it will be missed if the two ears were compared. Blood supply of the two tympanic membranes is centrally controlled, thus if inflammation causes congestion of one tympanic membrane then the blood supply of the other tympanic membrane may be increased sympathetically. Furthermore, if we study the pathogenesis of AOM then we see that upper respiratory tract infection is the leading cause of AOM which can affect both the Eustachian tubes and thus both the ears in many cases. Jolin et al. ${ }^{15}$ studied patients of AOM with suppuration and similarly Aniutin et al. ${ }^{11}$ studied patients with exudative otitis media (EOM). However, in our study we excluded patients with ear discharge, as discharge is a physical barrier and is likely to interfere with the detection of infra-red emission from the tympanic membrane. In addition, the diagnosis of AOM in nonotologic setup is more difficult when there is no ear discharge, so tympanic thermometry if used as a diagnostic or screening tool for AOM, will be more helpful in patients without ear discharge. Brennan et al., found that in patients with unilateral $A O M$, the infected ears were warmer than the uninfected ears however the difference was not statistically significant. ${ }^{10}$ This finding was also replicated in our study.

\section{Conclusion}

In acute otitis media, the temperature of affected ear was significantly higher than axilla but was not significantly higher than the other ear. This finding may help establish thermometry as a diagnostic tool in clinics manned by doctors not competent to do otoscopy

\section{References}

1. El-Radhi AS, Barry W. Thermometry in paediatric practice. Arch Dis Child 2006; 91(4):351-6. doi: 10.1136/adc.2005.088831

2. Long SS, Pickering IK, Prober CG, "Otitis media" in Principles and Practice of Pediatric Infectious Diseases, $4^{\text {th }}$ ed. USA.2012.

3. Liese JG, Silfverdal SA, Giaquinto C, Carmona A, Larcombe JH, Garcia-Sicilia J. et al. Incidence and clinical presentation of acute otitis media in children aged $<6$ years in European medical practices. Epidemiol Infect. 2014; 142(8): 1778-88. doi:10.1017/S0950268813002744.

4. Mustafa G, Al Aidaroos AY, Al Abaidani IS, Meszaros K, Gopala M, Ceyhan M et al. Incidence and economic burden of acute otitis media in children aged up to 5 years in three middle eastern countries and Pakistan: A multinational, retrospective, observational study. J Epidemiol Glob Health. 2017; 7(2): 123-30. doi: 10.1016/j.jegh.2016.12.004

5. McCarthy PW, Heusch Al. The vagaries of ear temperature assessment. J Med Eng Technol. 2006; 30 (4):241-51. doi: 10.1080/03091900600711415

6. Haddock BJ, Merrow DL, Swanson MS. The falling grace of axillary temperature. Pediatr. Nurs. 1996; 22:121-25. PMID: 8715845

7. Childs C, Harrison R, Hodkinson C. Tympanic membrane temperature as a measure of core temperature. Arch. Dis. Child. 1999; 80(3):262-66. 
8. Robb PJ, Shahab R. "Infrared transtympanic temperature measurement and otitis media with effusion". Int. J. Pediatr. Otorhinolaryngol. 2001; 59(3):195-200. doi: 10.1016/S01655876(01)00482-7

9. Doğan HH, Sezer RG, Kırkgöz T, Bozaykut A. Comparison of Axillary and Tympanic Temperature Measurements in Children Diagnosed with Acute Otitis Media. Int. J. Pediatr. 2016. ID 1729218. doi:10.1155/2016/1729218

10. Brennan DF, Falk JL, Rothrock SG, Kerr RB. Infrared tympanic thermometry in the evaluation of pediatric acute otitis media. Acad Emerg Med. 1994; 1(4):354-9. doi: 10.1111/j.1553-2712. 1994.tb02643.x

11. Aniutin RG, Ivkina SV, Dmitriev NS, Mileshina NA. Tympanic thermometry in diagnosis of exudative otitis media in children. Vestn Otorinolaringol. 2004; (2):33-5. PMID: 15111947
12. Hasel KL, Erickson RS. Effect of cerumen on infrared ear temperature measurement. J Gerontol Nurs. 1995;21(12):614. PMID: 8537621

13. Terndrup TE, Wong A. Influence of Otitis Media on the Correlation Between Rectal and Auditory Canal Temperatures. Am J Dis Child. 1991; 145(1):75-78. doi:10.1001/archpedi.1991.02160010081020

14. Kelly B, Alexander D. Effect of otitis media on infrared tympanic thermometry. Clin Pediatr (Phila). 1991; 30(4): 468. doi: $10.1177 / 0009922891030004 S 13$

15. Jolin SW, Howell JM, Milzman DP, Stair TO, Butzin CA. Infrared emission detection tympanic thermometry may be useful in diagnosing acute otitis media. Am J Emerg Med. 1995; 13(1): 6-8. doi: 10.1016/0735-6757(95)90230-9. 